\title{
Eksplorasi Tumbuhan Obat Antidiabetes di Kecamatan Tuah Negeri Kabupaten Musi Rawas
}

\section{Exploration Of Antidiabetic Medical Plantis In Tuah Negeri District, Musi Rawas Regency}

\author{
Fitria Lestari ${ }^{1 *}$, Yunita $^{1}$ \\ 1Program Studi Pendidikan Biologi, STKIP PGRI Lubuklinggau, \\ Lubuklinggau
}

Received: 29 April 2021;

Accepted: 04 Juni 2021;

Published: 07 Juni 2021

KATA KUNCI KEYWORDS

ABSTRAK

ABSTRACT
Tumbuhan Obat, Antidiabetes, Tuah Negeri Medical Plant, Antidiabetic, Tuah Negeri

Diabetes merupakan penyakit pembunuh ketiga di Indonesia dengan persentase $6,7 \%$, setelah stroke $(2,1 \%)$, dan jantung koroner $(12,9 \%)$. Jika penyakit ini tidak ditangani maka dapat menyebabkan penurunan disabilitas, produktivitas, dan kematian dini. Umumnya masyarakat menggunakan obat sintetis untuk mengobatinya, namun penggunaan obat ini jika digunakan dalam jangka waktu yang lama akan berdampak negatif bagi tubuh, seperti kerusakan ginjal. Oleh karena itu, salah satu solusi untuk meminimalisir dampak dari penggunaan obat sintetis itu, yaitu menggunakan tumbuhan obat berpotensi antidiabetes. Salah satu kecamatan di Kabupaten Musi Rawas yang memiliki potensi tumbuhan obat cukup melimpah, yaitu di Kecamatan Tuah Negeri. Lokasi penelitian dipilih sebanyak enam lokasi berdasarkan pertimbangan keberadaan tumbuhan obat. Teknik pengumpulan data dilakukan dengan observasi, wawancara, dokumentasi, dan identifikasi dengan menggunakan referensi. Hasil penelitian menunjukkan bahwa terdapat 15 jenis tumbuhan obat berpotensi antidiabetes.

Diabetes is the killer disease in Indonesia with a percentage of 6,7\%, after stroke $(2,1 \%)$ and coronary heart disease (12,9\%). If this fisease isb't treated, it can lead to decreased disability, productivity and premature death. Generally, people use synthetic drugs to treat it, but the use of these drugs if used for a long time will have a negative impact on the body, such as kidney damage. Therefore, one solution to minimize the impact of using synthetic drugs is to use medicinal plants that have the potential to be antidiabetic. One of the districts in Musi Rawas Regency that has the potential for medicinal plants is quite abundant, namely in the Tuah Negeri district. Six location for the study were selected based on the considered of the presence of medicinal plants. The data collection technique is done by observing, intervieweing, documenting, and identifying bu using references. The results that were 16 species that have a potention to medicinal plant as antidiabetic.
*Correspondence:

Email: Fitring@gmail.com 


\section{Pendahuluan}

Diabetes Mellitus (DM) atau sering dikenal dengan kencing manis merupakan penyakit kelainan metabolisme yang disebabkan kurangnya hormon insulin. Diabetes mellitus diartikan pula sebagai penyakit metabolisme yang termasuk dalam kelompok gula darah yang melebihi batas normal atau hiperglikemia (lebih dari 120 $\mathrm{mg} / \mathrm{dl}$ atau $120 \mathrm{mg} \%$ ), disebut juga penyakit gula (Darmawan, 2012). Menurut Suiraoka (2012) penyakit diabetes mellitus merupakan penyakit degeneratif yang menunjukkan proses penghancuran sel yang disertai adanya penurunan daya tahan sel saraf, sehingga mengakibatkan kematian sel lebih cepat.

Menurut data yang dikeluarkan oleh International Diabetes Federation (IDF) tahun 2015, jumlah penyandang diabetes di Indonesia mencapai 10 juta orang. Menurut data Sample Registration Survey tahun 2014, diabetes merupakan penyebab kematian terbesar nomor 3 di Indonesia dengan persentase sebesar 6,7 \%, setelah Stroke $(21,1 \%)$ dan penyakit jantung koroner $(12,9 \%)$. Jumlah penderita diabetes di Indonesia mengalami peningkatan di tahun 2019 mencapai 10,7 juta jiwa sehingga menjadikan Indonesia menduduki peringkat ketujuh dunia (Sari et al., 2020). Bila tidak di tanggulangi kondisi ini dapat menyebabkan penurunan kematian dini (Kementrian Kesehatan RI, 2016).

Selama ini, masyarakat Indonesia masih dominan menggunakan obat kimia dibandingkan obat herbal/tradisional dikarenakan cepatnya respon obat kimia dalam menurunkan kadar gula darah. Menurut departemen kesehatan RI (2005:36), obat kimia yang digunakan untuk mengatasi penyakit diabetes berupa golongan obat dari sulfonylurea, meglitinida, turunan fenilalanin, biguanida, tiazolidindion, inhibitor a-glukosidasae. Obat-obat kimia ini tidak baik untuk dikonsumsi dalam jangka waktu lama karena akan menimbulkan penyakit lainnya. Sanjoyo (2014) bahwa konsumsi obat farmakologi dapat mengakibatkan penurunan kerja ginjal, utamanya interstitial nefritis dan glomerulonefritis. Oleh karena itu, untuk mengurangi dampak negatif dari konsumsi obat kimia, tumbuhan obat tradisional merupakan salah satu solusinya (Sari et al., 2020). Tumbuhan obat diharapkan dapat menjadi alternatif untuk mengurangi penggunaan dan dampak jangka panjang dari obat kimia yang beredar di pasaran (Lestari dan Ivoni, 2019). Salah satu kecamatan di Kabupaten Musi Rawas yang memiliki banyak tumbuhan obat adalah Kecamatan Tuah Negeri.

Berdasarkan hasil observasi dan wawancara dengan masyarakat diketahui bahwa tumbuhan obat cukup melimpah yang ditanam dipekarangan rumah ataupun yang tumbuh secara liar. Informasi dari Dinas Kesehatan Kabupaten Musi Rawas (2018) diketahui bahwa penderita diabetes diperkirakan 127 dari 1.910 jiwa yang ada di kecamatan tersebut. Namun, banyaknya tumbuhan obat tidak diiringi dengan pengetahuan mengenai jenis Tumbuhan untuk mengobati penyakit tersebut. Adanya kesenjangan tersebut, mendorong peneliti untuk mengeksplorasi tumbuhan 
obat antidiabetes secara rinci, sehingga kedepannya data tersebut dapat didokumentasikan dan dimanfaatkan sebagai cara untuk meminimalisir penggunaan obat kimia.

\section{Metode Penelitian}

Pengambilan data dilapangan dilaksanakan pada Januari s.d Maret 2021 di kecamatan Tuah Negeri Kabupaten Musi Rawas. Pemilihan lokasi penelitian berdasarkan pertimbangan, yaitu: 1) daerah tersebut memiliki potensi tumbuhan obat yang banyak, 2) kayanya pengetahuan masyarakat akan pemanfaatan tumbuhan obat, dan 3) belum pernah dilakukan pendataan tumbuhan obat yang ada di daerah tersebut. Berdasarkan pertimbangan tersebut, terdapat enam desa yang memenuhi kriteria, yaitu: Petunang, Darma Sakti, Remayu, Jaya Tunggal, Jaya Bakti, dan Banpres.

Teknik pengumpulan data melalui: 1) tahap observasi dimana peneliti melakukan pengamatan langsung dan menggali informasi dari masyarakat yang menggunakan tumbuhan obat sebagai antidiabetes dengan instrumennya berupa lembar observasi. 2) tahap wawancara dengan menggunakan lembar wawancara dimana peneliti mewawancarai penderita diabetes, penjual jamu, dan masyarakat setempat yang sering memanfaatkan tumbuhan obat sebagai antidiabetes dengan berpedoman pada pertanyaan yang telah dipersiapkan. 3) Dokumentasi Tumbuhan sebagai bukti keberadaan tumbuhan obat berupa foto tumbuhan langsung di lapangan.

Teknik analisis data dalam penelitian ini menggunakan analisis deskriptif kualitatif. Data hasil wawancara dan observasi dikelompokkan berdasarkan spesies tumbuhan obat yang diketahui dan digunakan oleh masyarakat di kecamatan Tuah Negeri.

\section{Hasil}

Berdasarkan hasil penelitian yang telah dilakukan di enam desa, tumbuhan yang berpotensi sebagai antidiabetes berjumlah 15 jenis tumbuhan (Tabel 1 dan 2).

Tabel 1. Jenis-jenis tumbuhan obat di kecamatan Tuah Negeri

\begin{tabular}{|c|c|c|c|c|c|}
\hline No & $\begin{array}{c}\text { Nama Spesies/ } \\
\text { Nama Ilmiah }\end{array}$ & Nama Lokal & Famili & $\begin{array}{c}\text { Organ yang } \\
\text { digunakan }\end{array}$ & $\begin{array}{c}\text { Cara } \\
\text { pengolahan }\end{array}$ \\
\hline 1. & Allium сера & Bawang Abang & Lilia pceae & Umbi & Diparut \\
\hline 2. & $\begin{array}{l}\text { Amaranthus } \\
\text { tricolor } L\end{array}$ & Bayam Abang & Amaranthaceae & Daun & Direbus \\
\hline 3. & $\begin{array}{l}\text { Coleus } \\
\text { scutellarioides }\end{array}$ & Iler & Lamiaceae & Daun & Direbus \\
\hline 4. & Tithoma & Insulin & Asteraceae & Daun & Direbus \\
\hline
\end{tabular}


diversifolia

\begin{tabular}{|c|c|c|c|c|c|}
\hline 5. & Psidium guajava & Moka & Myrtaceae & Daun & Direbus \\
\hline 6. & $\begin{array}{l}\text { Archidendron } \\
\text { pauciflorum }\end{array}$ & Jeheng & Mimosaceae & Kulit & Direbus \\
\hline 7. & Gardenia augusta & Kaca Piring & Rubiaceae & Daun & Direbus \\
\hline 8. & Isotoma longiflora & Daon Katarak & Campanulaceae & Bunga & Ditetes \\
\hline 9. & $\begin{array}{l}\text { Phaleria } \\
\text { macrocarpa }\end{array}$ & Mahkota Dewa & Thymelaeaceae & $\begin{array}{l}\text { Daging } \\
\text { buah }\end{array}$ & $\begin{array}{l}\text { Dikeringkan } \\
\text { dan diseduh }\end{array}$ \\
\hline 10. & Mangifera indica & Mangga & Anacardiaceae & Daun & Direbus \\
\hline 11. & Morinda citrifolia & Mengkudu & Rubiaceae & Buah, daun & $\begin{array}{l}\text { Ditumbuk } \\
\text { ditempelkan }\end{array}$ \\
\hline 12. & $\begin{array}{l}\text { Arthocarpus } \\
\text { integra }\end{array}$ & Nake & Moraceae & Daun & Direbus \\
\hline 13. & Laucena glauca & Petai cine & Fabaceae & Biji & Ditumbuk \\
\hline 14. & $\begin{array}{l}\text { Tetracera indica } \\
\text { Merr }\end{array}$ & Ako hepet & Dilleniaceae & Daun, akar & Direbus \\
\hline 15. & $\begin{array}{l}\text { Cantharanthus } \\
\text { roseus }\end{array}$ & Bunge jam & Apocynaceae & Daun & Direbus \\
\hline
\end{tabular}

Tabel 2. Jenis tumbuhan obat antidiabetes di Kecamatan Tuah Negeri

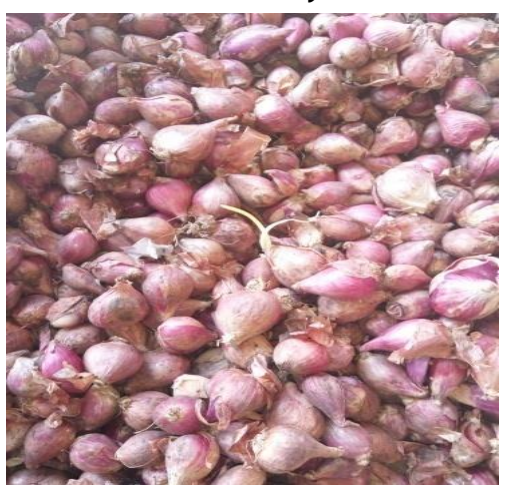

Allium cepa $L$

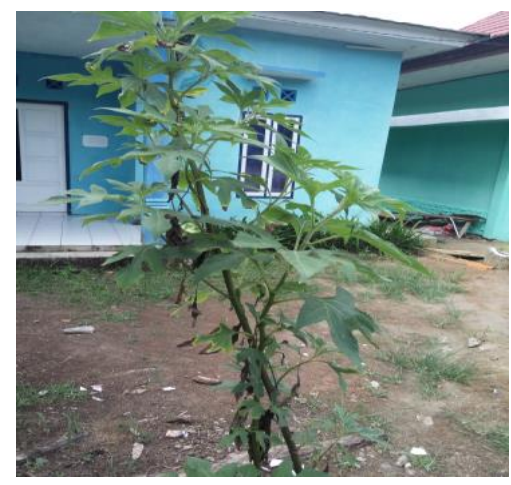

Tithoma diversifolia

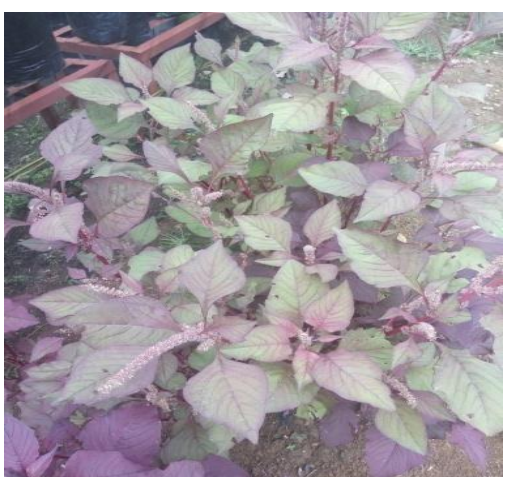

Amaranthus tricolor $L$

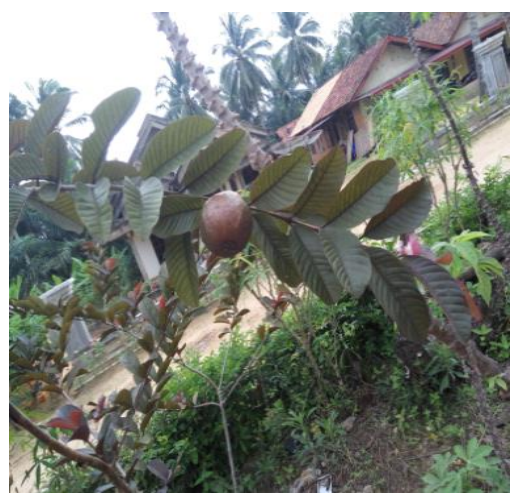

Psidium guajava

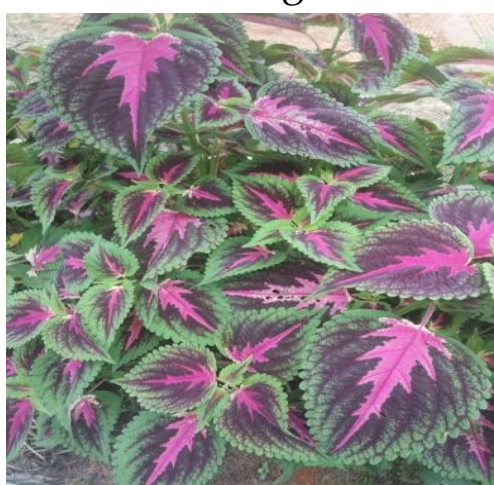

Coleus scutellarioides

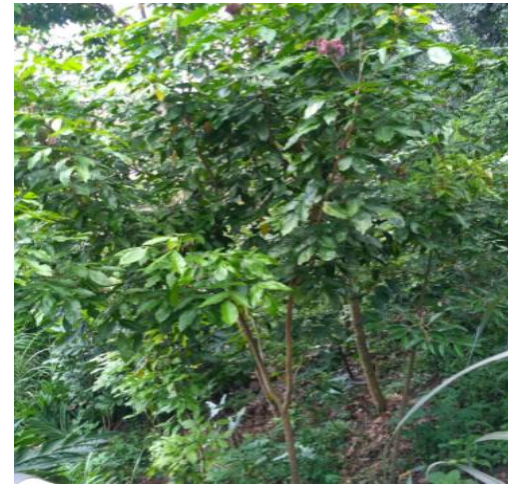

Archidendron pauciflorum 


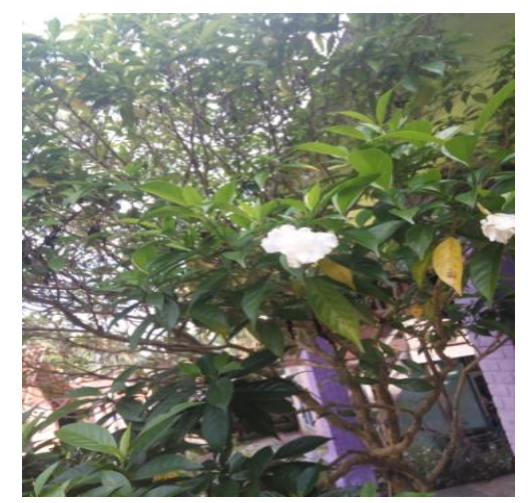

Gardenia mangostana

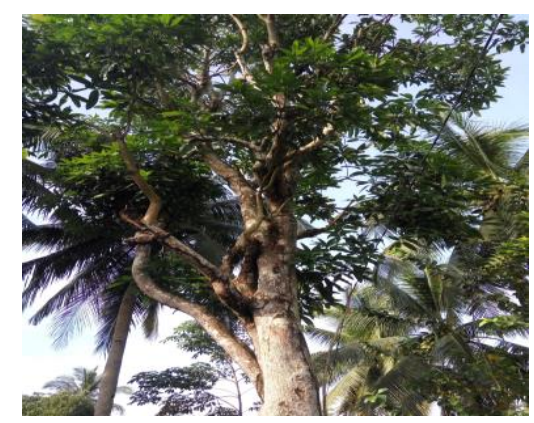

Mangifera indica

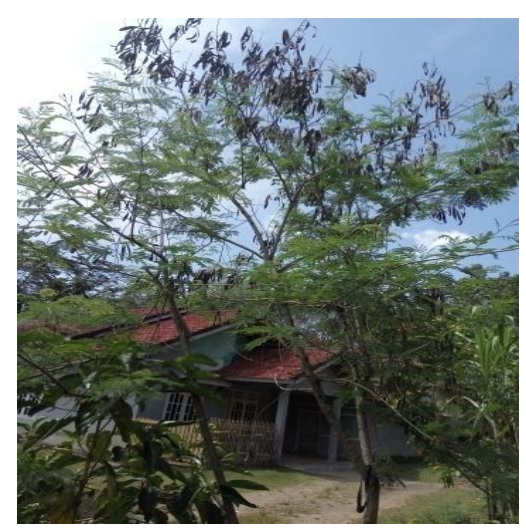

Leucena glauca

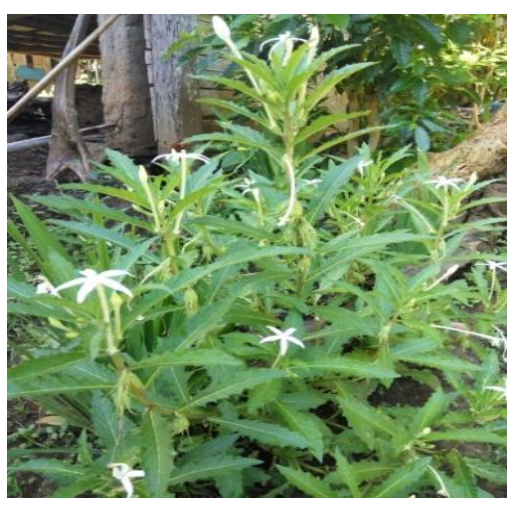

Isotoma longiflora

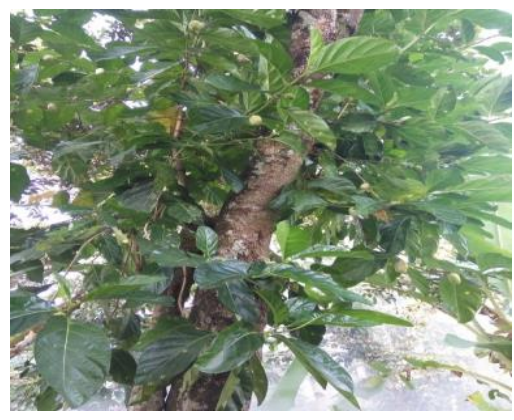

Morinda citrifolia

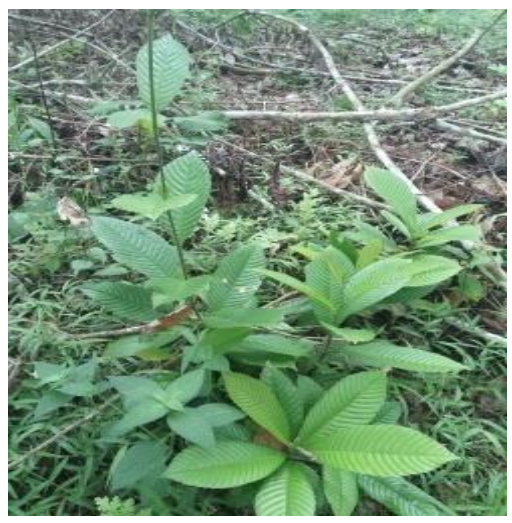

Tetracera indica $\mathrm{M}$

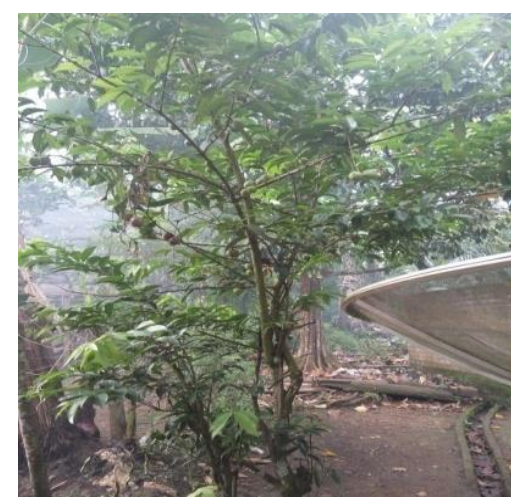

Phaleria macrocarpa

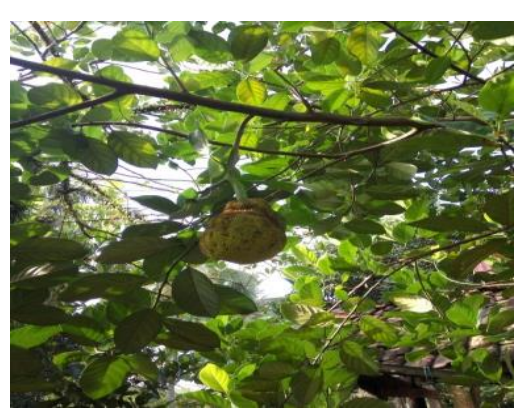

Arthocarpus integra

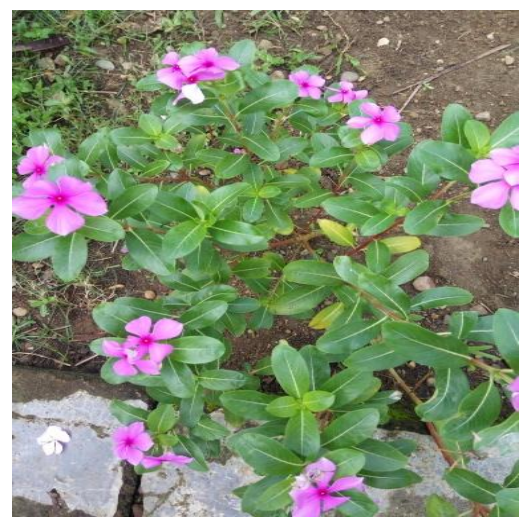

Cantharanthus roseus

Jenis-jenis famili dari tumbuhan obat yang ditemukan di Kecamatan Tuah Negeri yaitu Liliaceae, Amaranthaceae, Lamiaceae, Asteraceae, Rubiaceae, Mimosaceae, Campanulaeae, Thymelaceae, Anacardinaceae, Moraceae, Piperaceae, Dilleniaceae, Apocynaceae, Fabaceae, dan Myrtaceae (Gambar 1). 


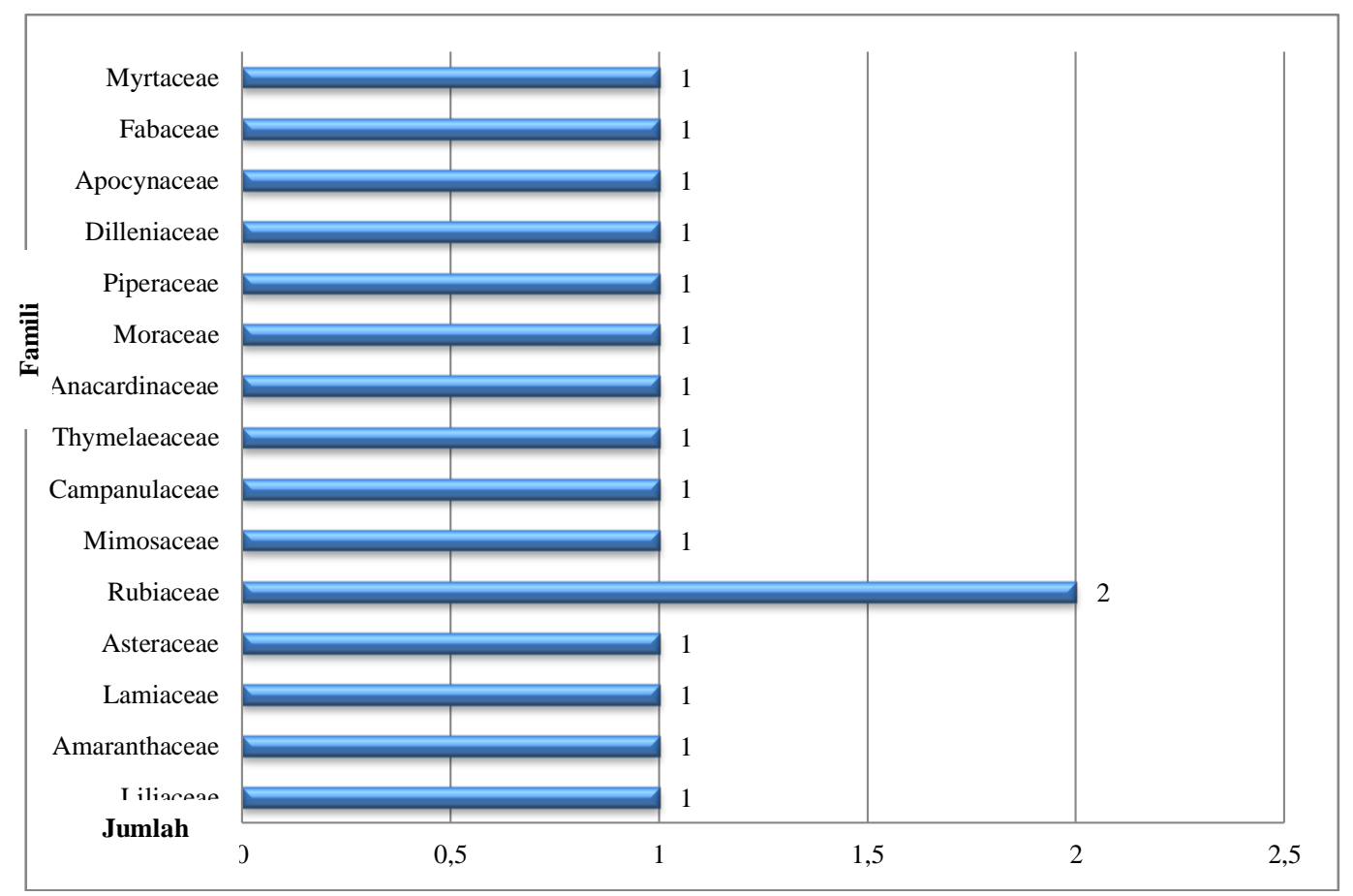

\section{Gambar 1 Jenis-Jenis Famili Tumbuhan Obat Antidiabetes di Kecamatan Tuah Negeri}

\section{Pembahasan}

Berdasarkan hasil observasi dan wawancara diketahui bahwa tumbuhan obat berpotensi antidiabetes yang ditemukan di Kecamatan Tuah Negeri berjumlah 15 jenis dari 15 famili. Masyarakat banyak memanfaatkan beberapa jenis tumbuhan obat diabetes mellitus yang diketahui berdasarkan pengetahuan tradisional secara turun-temurun. Desa tempat ditemukannya banyak tumbuhan obat adalah di Desa Petunang dan Desa Darma Sakti, karena tingkat kesadaran masyarakat akan kesehatan dengan memanfaatkan tumbuhan obat masih tinggi, masih tersedianya lahan untuk ditumbuhi oleh tumbuhan obat dan adanya penderita diabetes mellitus yang cukup banyak. Empat desa yang tersisa tidak digunakan dikarenakan sedikitnya ketersediaan lahan didaerah ini dan padatnya pemukiman masyarakat.

Berdasarkan hasil penelitian diketahui bahwa famili Rubiaceae merupakan famili yang paling banyak digunakan sebagai obat diabetes oleh masyarakat kecamatan Kecamatan Tuah Negeri yaitu dua jenis tumbuhan diantaranya Gardenia augusta (Kaca Piring) dan Morinda citrifolia (Mengkudu). Kandungan senyawa yang ada pada daun Gardenia augusta (Kaca Piring) yaitu senyawa tanin dan alkaloid (Sangi, 2008). Hal ini didukung oleh Chasani et al. (2011) bahwa daun tumbuhan kaca piring berpotensi sebagai antidiabetes. Senyawa kimia yang terdapat pada daun Morinda citrifolia (mengkudu), yaitu antrakuinon, glikosida, dan karotin. Sedangkan yang terdapat pada buahnya yaitu terpenoid, xeronn, dan proxeronin Nuraini (2014:138). 
Hal ini sesuai dengan penelitian Widuri et al. (2013) yang menguji 14 spesies tumbuhan dan diperoleh 5 spesies tumbuhan yang berpotensi sebagai obat diabetes mellitus karena memiliki kandungan metabolit sekunder seperti alkaloid, flavonoid, tanin, steroid, saponin, polifelonat, kuinon dan triterpenoid. Tumbuhan obat adalah tumbuhan yang berpotensi untuk mengobati berbagai macam penyakit dikarenakan adanya kandungan berbagai senyawa didalamnya (Lestari dan Ivoni, 2020). Berdasarkan senyawa yang terkandung diatas tumbuhan antidiabetes yang di temukan, rata-rata memiliki senyawa dominan flavonoid. Senyawa flavonoid berfungsi menetralkan radikal bebas dan mencegah kerusakan sel beta pada pankreas dalam memproduksi hormon insulin untuk mengurangi kadar gula darah tubuh (Arjadi, 2010).

\section{Kesimpulan}

Jenis-jenis tumbuhan obat antidiabetes yang ditemukan di Kecamatan Tuah Negeri terdiri dari 15 jenis tumbuhan. Pada Desa Petunang dan Desa Darma Sakti sebanyak 7 jenis, sedangkan Desa Remayu, Desa Jaya Tunggal, Desa Jaya Bakti, dan Desa Banpres masing-masing sebanyak 6 jenis.

\section{Ucapan Terima Kasih}

Ucapan terima kasih penulis sampaikan kepada STKIP PGRI Lubuklinggau dan Camat Kecamatan Tuah Negeri yang telah berkontribusi dalam penelitian ini.

\section{Daftar Pustaka}

Arjadi, F. dan Pryo, S. 2010. Regenearasi Sel Pulau Langerhans Pad Tikus Putih Diabetes yang diberi Rebusan Daging Mahkota Dewa. Jurnal Medincal Faculty of Jendral Sudirman. 2 (2)

Chasani, M., Hartiwi, D., dan Rizka, A. 2011. Pemurnian, Identifikasi, dan Uji Aktivitas Antidiabetes Senyawa Metabolit Sekunder Ekstrak Etil Asetat Daun Kaca Piring (Gardenia augusta Merr). Eksakta, 12 (2)

Darmawan. 2012. Waspadai Gejala Penyakit Mematikan Jantung Koroner dengan tiga jenis Penyakit yang Berkaitan: Hipertensi, Diabetes Mellitus, dan Stroke. Jakarta Selatan: PT. Suka Buku.

Departemen Kesehatan RI. 2005. Pharmaceutical Care untuk Penyakit Diabetes Mellitus. (Online, Farmalkes.kemenkes.go.id/) diakses pada tanggal 13 Maret 2021.

Dinas Kesehatan Musi Rawas. 2018. Rencana Strategis (RENSTRA) Dinas Kesehatan Kabupaten Musi Rawas 2016-2021. Musi Rawas

IDP. 2015. IDF Diabtes Atlas. International Diabetes Federation. Jurnal International 
Diabetes Federation. doi:10.1289/image.ehp.v119.i03

Jennifer H dan Endah, S. 2015. Preferensi Individu Terhadap Pengobatan Tradisonal Di Indonesia. Jurnal Ekonomi dan Studi Pembangunan. 16 (1).

Kementrian Kesehatan RI. 2016. Menkes: Mari Kita Cegah Diabetes Dengan Cerdik. (Online, http://www.depkes.go.id/) diakses pada tanggal 13 Maret 2021.

Lestari, F., dan Ivoni, S. 2019. Eksplorasi Proses Pengolahan Tumbuhan Obat Imunomodulator Suku Anak Dalam Bendar Bengkulu. Bioedukasi: Jurnal Pendidikan Biologi. 10 (2)

Lestari, F., dan Ivoni, S. 2020. Tumbuhan Obat Berpotensi Imunomodulator di Suku Anak Dalam Bendar Bengkulu. JPBIO (Jurnal Pendidikan Biologi). 5(1).

Nuraini. 2014. Daun Berkhasiat Obat. Yogyakarta: Penerbit Gava Media.

Pranata, S. 2014. Herbal TOGA (Tanaman Obat Keluarga). Yogyakarta: Aksara Sukses.

Sangi. 2018. Analisis Fitokimia Tumbuhan Obat di Kecamatan Minahasa Utara. Jurnal Chem, 1 (1). 47-53.

Sanjoyo, R. 2018. Obat (Biomedik Farmakologi). (Online, http:/ / www.yoyoke.web.ugm.ac.id), diakses tanggal 12 Mei 2019.

Sari M.S., Ridwan A., Mardina V., Putri K.A., Alfajar B., Wibowo S.G. 2020. Skrining Potensial Pinang Aceh (Areca catechu L.) Sebagai Elevator Transporter GLUT4 dan Fitokonstituen Antiproliferatif Sel Kanker. Herbal Medicine Journal, 3 (1): 6 - 11.

Steenis, V. C.G.G.J. 2006. Flora. Jakarta: PT Pradnya Paramita

Sugiyono. 2012. Metode Penelitian Pendidikan Pendekata Kuantitatif Kualitatif dan RED. Bandung: Penerbit Alfabeta

Suiraoka. 2012. Penyakit degenerative Mengenal, Mencegah dan Mengurangi Faktor Reisko 9 Penyakit Degeneratif. Yogyakarta: Nuha Medika.

Tjitrosoepomo, G. 2011. Morfologi Tumbuhan. Yogyakarta: Gadjah Mada University Press

Widuri S.A, Noorcahyati, Antun P. 2013. Potensi Beberapa Jenis Tumbuhan Berkhasiat Antidiabetes oleh Etnis Kalimantan Sebagai Sumber Metabolit Sekunder untuk Pengembangan Obat Modern. Jurnal Penelitian Teknologi Konservasi Sumber Daya Alam. 